\title{
Genotyping Staphylococcus aureus Isolates with RS-PCR from Chicken Meat in Chennai City
}

\author{
S. J. Deepak, K. Porteen", A. Elango, T. M. A. Senthil Kumar, \\ R. Narendra Babu, S. Sureshkannan and S. Wilfred Ruban \\ Department of Veterinary Public Health and Epidemiology, Madras Veterinary College, \\ TANUVAS, Chennai 600007, India \\ *Corresponding author
}

\section{A B S T R A C T}

Keywords

S. aureus,

Ribosomal spacer-

PCR, 16S-23S

ribosomal spacer

region,

Phylogenetic tree,

Evolutionary

analysis

Article Info

Accepted:

17 November 2019

Available Online:

10 December 2019
The Staphylococcus aureus is a versatile opportunistic pathogen affecting both human and animals. The Genotyping of $S$. aureus isolates helps to understand the pathogen's dissemination and epidemiological clusters, Hence, the present study designed to study the genotyping Staphylococcus aureus with RS-PCR from Chicken meat in Chennai City. In the present study, ribosomal spacer PCR (RS-PCR) was found to be showing polymorphism with varying band size and on software based dendrogram analysis. The dendrogram obtained upon analysis found that 3 main clusters and named as Cluster A, Cluster B and Cluster C. The similarity co-efficient at 0.05 they were characterised as 23 ribotypes. The most frequent ribotype belong to Cluster $\mathrm{C}$ and ribotype no 23. Based on Cluster analysis in our study revealed that may be single evolutionary originated epidemiological similar S. aureus strain is circulating and its clustered with transmitted in chicken meat though out the city thou meat was not collected from the same farm or site. The PCR ribotyping is a rapid inexpensive technique that is highly reproducible and almost as discriminatory as other typing methods for $S$. aureus isolates and should be useful in the local investigation and control of outbreaks.

\section{Introduction}

Staphylococcus aureus is a versatile opportunistic pathogen (Sergelidis and Angelidis, 2017) example for amphixenosis which mainly involved in inter-transmission of diseases between humans and animals. The organism pathogenicity mainly depends on combination of genetic characteristics between different variants mediating virulence, immune evasion, invasive capacity, and antibiotic resistance (Chua et al., 2014). They harbour variety of virulence factors which includes toxic shock syndrome toxin-1 (TSST1), exfoliative toxin, enterotoxins, PantonValentine leukocidin and enterotoxin-like (Kot et al., 2016; Wang and Muir, 2016). They are often being isolated from meat, raw milk, the processing surfaces and food handlers (Johler et al., 2018). S. aureus strains major concern is antibiotic resistance evolving deadly Methicillin-resistant S. aureus (MRSA) 
acquiring the mecA gene, encoding penicillinbinding protein 2a (PBP2a) and making treatment against them a tough battle (Fishovitz et al., 2015). MRSA and other antimicrobial resistant $S$. aureus constitutes a serious public-health concern as they can affect humans, animals and presence in environment (Petinaki and Spiliopoulou, 2012).

The important routes of transmission of $S$. aureus are foods and food chains between food-producing animals and humans and vice versa (EFSA, 2009; Feingold et al., 2012). Similarly, community-associated MRSA has been isolated from several animal-source foods such as poultry, pork and beef (Wang and Muir, 2016). Animals can act as source of zoonotic infections of $S$. aureus, most strains lack specific host tropism affecting many species (Luini et al., 2015).

The Genotyping of S. aureus isolated from various sources and sites helps to understand the pathogen's dissemination and epidemiological clusters (Castelani et al., 2013). The biochemical and molecular methods were earlier used for epidemiological investigations of human and bovine staphylococcal infections (Hartstein et al., 1989; Kapur et al., 1995). The introduction of PCR based genotyping methods are useful techniques because of sensitivity and speed of performance. RAPD-PCR based tool was used for molecular taxonomy and phylogenetic analysis among related individuals (Williams et al., 1990). The repetitive element palindromic PCR (REP-PCR) and enterobacterial repetitive intergenic consensus sequence analysis (ERIC-PCR) were also used for discrimination of strains (Lessing et al., 1995). The Pulsed-field gel electrophoresis (PFGE) has been recommended as a highly discriminatory method for typing MRSA but method is time-consuming and expensive typing method not well suited for screening large number of isolates (Tenover et al., 1995).The similar PCR based amplification of the 16S-23S rRNA of intergenic spacer region (ribosomal spacer-PCR, RS-PCR) was found to be more valid in understanding evolutionary interest since there is sufficient conservation within this locus a universal organization of evolutionary relationships (Cedergren et al., 1993). The 16S, 23S, and 5S rRNA genes are separated by spacer regions which exhibit significant sequence and length polymorphisms at the genus and species levels (Jensen et al., 1993). The PCR based amplification of $16 \mathrm{~S}-23 \mathrm{~S}$ ribosomal spacer region can act as suitable method in generating database (Jensen et al., 1993). The ribosomal spacer PCR technique has the advantage that it is less prone to variation because it is specific and is performed under high stringency conditions. Analysis of these sequences has been useful in differentiating closely related members of a number of genera. The present study designed to study the molecular based genotyping using RSPCR of $S$. aureus isolates from chicken meat in Chennai city.

\section{Materials and Methods}

\section{Sample}

A total of 259 chicken meat samples were collected aseptically using sterile Ziplocks from various retail vendors in the Chennai city. The study period from May 2017 to May 2019. The samples were transported to laboratory under refrigeration and stored at $4^{\circ} \mathrm{C}$ until further processing.

\section{Isolation of Staphylococcus aureus}

The chicken meat sample was enriched in brain heart infusion broth (HiMedia, India) containing $5-7 \% \mathrm{NaCl}$ at $1: 10$ dilution and incubated at $35-37^{\circ} \mathrm{C}$ for $18-24 \mathrm{~h}$. The enriched samples plated on Mannitol salt agar 
(MSA) (HiMedia, India) incubated for $24 \mathrm{~h}$ at $35-37^{\circ} \mathrm{C}$. The characteristic appearance of golden yellow colour colonies was considered to be presumptive $S$. aureus. The organism was demonstrated by Gram's stained smears which show Gram-positive cocci that occurred in grape like clusters. Further confirmation was done by positive reaction with catalase test (3\% hydrogen peroxide), coagulase test using rabbit plasma and latex agglutination test (HiMedia, India).

\section{DNA preparation}

The 2-3 colony of presumptive isolates were transferred in $100 \mu \mathrm{L}$ of sterile nuclease free water and washed thrice and the DNA was extracted by the boiling-snap chill method viz., boiling at $100^{\circ} \mathrm{C}$ for $5 \mathrm{~min}$, followed by immediate chilling for $5 \mathrm{~min}$ at $-20^{\circ} \mathrm{C}$ and then centrifuged at $10000 \mathrm{rpm}$ for $5 \mathrm{~min}$ at $4^{\circ} \mathrm{C}$, recovering the supernatant. The supernatant was used as DNA template for PCR reaction mixture.

\section{PCR based ribotyping method for genotyping}

The oligonucleotide primers G1-5, GAAGTCGTAACAAGG and L1- 5' CAAGGCATCCACCGT were used for amplification of $16 \mathrm{~S}-23 \mathrm{~S}$ ribosomal DNA inter spacer region $S$. aureus isolates as described by Jensen et al., (1993). The polymerase chain reaction was performed in a reaction mixture of $25 \mu \mathrm{L}$ of final volume approximately containing $100 \mathrm{ng}$ of template DNA, $12.5 \mu \mathrm{L}$ of Taq DNA polymerase $2 \mathrm{X}$ Master mix (Amplicon III, Denmark), $1 \mu \mathrm{L}$ of (20 pmol) each primer (Sigma Aldrich, India) and made up volume by nuclease free water. The PCR conditions in an A200 Gradient Thermal Cycler (LongGene®, Hangzhou, China) consisted of initial denaturation $94^{\circ} \mathrm{C}$ for $5 \mathrm{~min}$, followed by 35 cycles of $94^{\circ} \mathrm{C}$ for $45 \mathrm{~s}, 55^{\circ} \mathrm{C}$ for $1 \mathrm{~min}$ and $72^{\circ} \mathrm{C}$ for $1 \mathrm{~min}$ with a final extension of $72^{\circ} \mathrm{C}$ for $7 \mathrm{~min}$. The amplified products were examined on agarose gel electrophoresis (1.5\%) and $0.5 \%$ ethidium bromide staining. The gel was visualized using Imagecapture software in BioRad Gel documenter. The banding pattern was compared and scored as binary matrix with ' 0 ' $\&$ ' 1 ' which denotes that presence of a particular band as 1 and 0 for absence of that particular band. The similarity matrix constructed, based on Dice's correlation coefficient and by the method of the mean genetic distances UPGMA (UnweightedPair Group Method for Arithmetic Averages) using the Freetreeprogram (0.9.1.50 version). The dendograms were obtained to assess the genetic relationship among the $S$. aureus isolates with RS-PCR were and visualized using the online Phylogenetic tree (newick) viewer by TreeDyn by Phylogeny.fr: robust phylogenetic analysis (Chevenet et al., 2006; Dereeper et al., 2008)

\section{Results and Discussion}

A total of 259 chicken meat samples when subjected for isolation of $S$. aureus using conventional methods, found that 41.31 percent (107/259) presumptive positive isolates. The presumptive Staphylococcus aureus isolates were further confirmed with latex agglutination test and coagulase test. The positive isolates were further subjected for DNA extraction and used for genotypic based RS-PCR typing using oligonucleotide primers G1 and L1 for the amplification of 16S-23S ribosomal DNA inter spacer region conserved fragments (Jensen et al., 1993). The total of 107 positive $S$. aureus isolates on typing with RS-PCR found that amplicon bands varying size from $350 \mathrm{bp}$ to $900 \mathrm{bp}$; with 3 to 8 fragments resolved per isolate (Figure 1). Similar kind of result was found with Reshma et al., (2017) who reported band size between $450 \mathrm{bp}$ to $1000 \mathrm{bp}$ and 1 to 10 fragments resolved in S. aureus isolates whereas Rao and 
Surendran, (2010) reported bands were narrow band spectrum between 530 and 870 bp in Vibrio choleare. The presence of more amplified products might be due to the fact that Staphylococcus aureus has 9 operons and the weaker band may represent heteroduplex molecules resulting from cross hybridization of amplification products from different kinds of operons.

The gel images were further subjected for similarity matrix construction, based on Dice's correlation coefficient, by the method of the mean genetic distances UPGMA (Unweighted Pair Group Method for Arithmetic Averages) using the Freetree program for phylogenetic tree construction. In the present study, ribosomal spacer PCR (RSPCR) was found to be showing polymorphism with varying band size and on software based dendrogram analysis. The 16S-23S intergenic sequence was showed as highly conserved, stable and appropriate indicator to study the evolutionary divergence of $S$. aureus strains (Gurtler and Barrie, 1995).

The dendrogram obtained upon analysis found that 3 main clusters and named as
Cluster A, Cluster B and Cluster C (Figure 2). The similarity co-efficient at 0.05 they were characterised as 23 ribotypes. The Cluster A and $\mathrm{B}$ comprised of 6 ribotypes each and Cluster C comprised of 11 ribotypes, respectively. The most frequent ribotypebelong to Cluster $\mathrm{C}$ and ribotype no 23. The remaining isolates were evenly distributed in 22 other ribotypes groups of smaller number per ribotype. Based on Cluster analysis in our study revealed that may be single evolutionary originated epidemiological similar $S$. aureus strain is circulating and its clustered with transmitted in chicken meat though out the city thou meat was not collected from the same farm or site. The spread of antimicrobial resistance gene and other virulence factors among the isolates since they have genetic relatedness would we major contributing factor. The results conclude that RS-PCR can be used for detection of polymorphism to know the genetic relatedness of $S$. aureus isolated from different sites. Though PCR based ribotyping can be used for the detection of polymorphism and to assess the genetic relatedness of $S$. aureus.

Figure.1 The gel image of S. aureus isolates on typing with RS-PCR

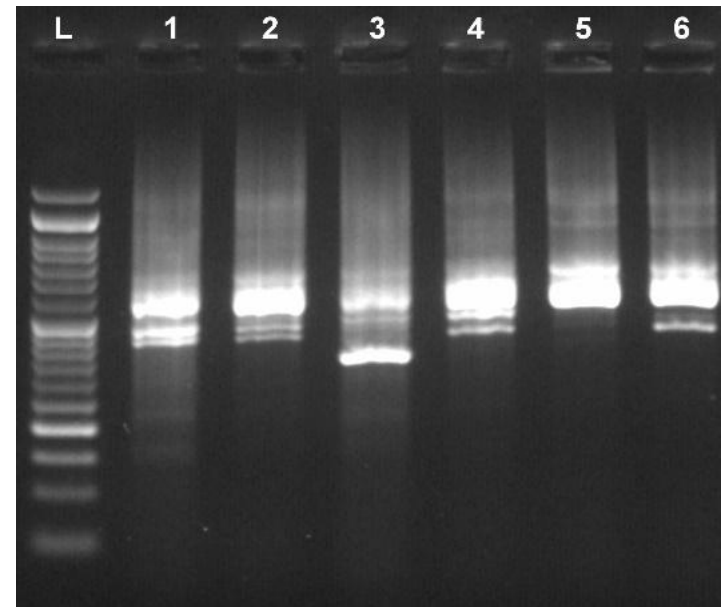

(L: DNA ladder (50bp); 1,2,3,4,5,6 - RS-PCR ribotypes showing polymorphism with band bands between 350bp900bp) 
Figure.2 The dendrogram showing clusters and ribotypes based on RS-PCR gel image analysis on Free tree software

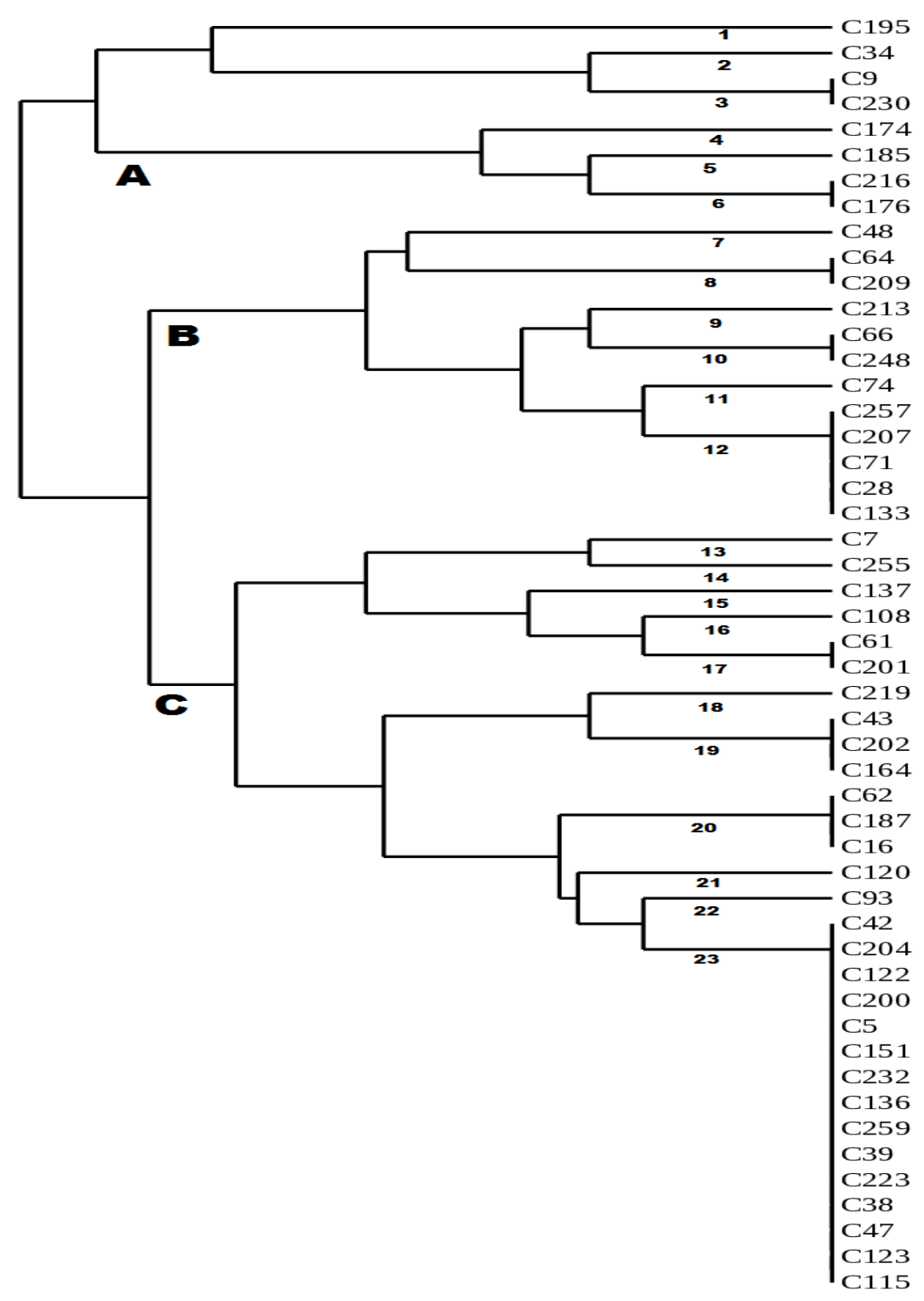

0.09

Other molecular techniques like Pulsed Field Gel Electrophoresis (PFGE), Multilocus sequence typing (MLST), Staphylococcal protein A $(S p a)$ typing and whole genome sequencing are required to establish zoonotic transmission of these strains from animals to animal handlers and vice versa.
In conclusion, the present study provides on input that ribosomal spacer PCR (RS-PCR) was found to be showing polymorphism with varying band size and on software based dendrogram analysis. There was considerable genetic heterogeneity in population of $S$. aureus isolated with this appropriate typing 
system to determine the genetic structures of the isolates, enabling a rational and effective strategy for epidemiological control. PCRribotyping is a rapid inexpensive technique that is highly reproducible and almost as discriminatory as PFGE for typing $S$. aureus isolates and should be useful in the local investigation and control of outbreaks.

\section{References}

Castelani, L., Santos, A.F., Dos Santos Miranda, M., Zafalon, L.F., Pozzi, C.R. and Arcaro, J.R. 2013. Molecular typing of mastitis-causing Staphylococcus aureus isolated from heifers and cows. Int. J. Mol. Sci., 14: 4326-4333

Cedergren, L., Andersson, R., Jansson, B., Uhlén, M. and Nilsson, B. 1993. Mutational analysis of the interaction between staphylococcal protein A and human IgG1. Protein Engineering, Design and Selection, 6(4): 441-448.

Cedergren, R. J., Gray, M. W., Abel, Y. and Sankoff, D. 1988.The evolutionary relationships among known life forms. J. Mol. Evol. 28:98-112.

Chevenet F., Brun C., Banuls AL., Jacq B. and Chisten R. 2006. TreeDyn: towards dynamic graphics and annotations for analyses of trees. BMC Bioinformatics. 7: 439.

Chua, K.Y., Monk, I.R., Lin, Y.H., Seemann, T., Tuck, K.L., Porter, J.L., Stepnell, J., Coombs, G.W., Davies, J.K., Stinear, T.P. and Howden, B.P. 2014. Hyper expression of $\alpha$-hemolysin explains enhanced virulence of sequence type 93 community-associated methicillinresistant Staphylococcus aureus. BMC microbiology, 14(1): 1 .

Dereeper A., Guignon V., Blanc G., Audic S., Buffet S., Chevenet F., Dufayard J.F., Guindon S., Lefort V., Lescot M., Claverie J.M. and Gascuel O. 2008. Phylogeny.fr: robust phylogenetic analysis for the non-specialist. Nucleic Acids Res. 36(1) 465-9.
EFSA J. 2009. Scientific Opinion of the Panel on Biological Hazards on a request from the European Commission on Assessment of the Public Health significance of methicillin resistant Staphylococcus aureus (MRSA) in animals and foods. 993: 1-73.

Feingold, B.J., Silbergeld, E.K., Curriero, F.C., van Cleef, B.A., Heck, M.E. and Kluytmans, J.A. 2012. Livestock density as risk factor for livestock-associated methicillin-resistant Staphylococcus aureus, the Netherlands. Emerging infectious diseases, 18(11): 1841.

Fishovitz, J., Taghizadeh, N., Fisher, J.F., Chang, M. and Mobashery, S. 2015. The Tipper-Strominger hypothesis and triggering of allostery in penicillinbinding protein $2 \mathrm{a}$ of methicillin-resistant Staphylococcus aureus (MRSA). Journal of the American Chemical Society, 137(20): 6500-6505.

Gurtler, V. and Barrie, H.D. (1995). Typing of Staphylococcus aureus strains by PCR amplification of variable-length 16S-23S rDNA spacer regions: characterization of spacer sequences. Microbiology, 141(5):1255-1265.

Hartstein, A.I., Morthland, V.H., Eng, S., Archer, G.L., Schoenknecht, F.D. and Rashad, A.L. 1989. Restriction enzyme analysis of plasmid DNA and bacteriophage typing of paired Staphylococcus aureus blood culture isolates. Journal of clinical microbiology, 27(8): 1874-1879.

Jensen, M.A., Webster, J.A. and Straus, N. (1993). Rapid identification of bacteria on the basis of polymerase chain reactionamplified ribosomal DNA spacer polymorphisms. Applied and Environmental Microbiology, 59(4): 945952.

Johler, S., Tichaczek-Dischinger, P.S., Rau, J., Sihto, H.M., Lehner, A., Adam, M. and Stephan, R. 2013. Outbreak of Staphylococcal food poisoning due to SEA-producing Staphylococcus aureus. Foodborne pathogens and disease, 10(9): 
777-781.

Kapur, V., Sischo, W.M., Greer, R.S., Whittam, T.S. and Musser, J.M. 1995. Molecular population genetic analysis of Staphylococcus aureus recovered from cows. Journal of clinical microbiology, 33(2): 376-380.

Kot, B., Szweda, P., Frankowska-Maciejewska, A., Piechota, M. and Wolska, K. 2016. Virulence gene profiles in Staphylococcus aureus isolated from cows with subclinical mastitis in eastern Poland. Journal of Dairy Research, 83(2): 228235.

Lessing, M. P. A., Jordens, J. Z. and Bowler, I. C. J. 1995. Molecular epidemiology of a multiple strain outbreak of methicillin resistant Staphylococcus aureus amongst patients and staff. J. Hosp. Infect. 31:253260.

Lessing, M.P.A., Jordens, J.Z. and Bowler, I.C.J., 1995. Molecular epidemiology of a multiple strain outbreak of methicillinresistant Staphylococcus aureus amongst patients and staff. Journal of Hospital Infection, 31(4): .253-260.

Luini, M., Cremonesi, P., Magro, G., Bianchini, V., Minozzi, G., Castiglioni, B. and Piccinini, R. 2015. Methicillin-resistant Staphylococcus aureus (MRSA) is associated with low within-herd prevalence of intra-mammary infections in dairy cows: Genotyping of isolates. Veterinary microbiology, 178(3-4): 270274.

Petinaki, E. and Spiliopoulou, I. 2012. Methicillin-resistant Staphylococcus aureus among companion and food-chain animals: impact of human contacts. Clinical Microbiology and Infection, 18(7): 626-634.

Rao, B.M. and Surendran, P.K. 2010 Genetic heterogeneity of non-O1 and non-O139 Vibrio cholerae isolates from shrimp aquaculture system: a comparison of RS-, REP- and ERIC-PCR fingerprinting approaches, Applied Microbiology, Letters in Applied Microbiology 51: 6574

Reshma, S., Srinivasa Rao, T., Madhava Rao, T., Metta, M. and Soma Sekhar, M. 2017. PCR-ribotyping of bovine and human methicillin resistant Staphylococcus aureus. International Journal of Science Environment and Technology, 6(3): 1790 $-1795$

Tenover, F. C., Arbeit, R. D., Goering, R. V., Micklesen, P. A., Murray, B. E., Persing, D. H. and Swaminathan, B. 1995. Interpreting chromosomal DNAresolution patterns produced by pulsed field gel electrophoresis: criteria for bacterial strain typing. J. Clin. Microbiol. 33:23332339.

Wang, B. and Muir, T.W. 2016. Regulation of virulence in Staphylococcus aureus: molecular mechanisms and remaining puzzles. Cell chemical biology, 23(2): 214-224.

Williams, J.G.K., Kubelik, A.R., Livak, K.J., Rafalski, J.A., Tingey, S.V. 1990. DNA polymorphisms amplified by arbitrary primers are useful as genetic markers. Nucl. Acids Res. 18, 6531-6535.

\section{How to cite this article:}

Deepak, S. J., K. Porteen, A. Elango, T. M. A. Senthil Kumar, R. Narendra Babu, S. Sureshkannan and Wilfred Ruban, S. 2019. Genotyping Staphylococcus aureus Isolates with RS-PCR from Chicken Meat in Chennai City. Int.J.Curr.Microbiol.App.Sci. 8(12): 2515-2521. doi: https://doi.org/10.20546/ijcmas.2019.812.294 